\title{
Alcohol Detection using Face Recognition Technique Integrated with Embedded System
}

\author{
Shreyas Joshi \\ B. E. (Computer) \\ Dept. of Computer Engg. \\ JSPM's PVPIT, Pune
}

\author{
Shreya Kate \\ B. E. (Computer) \\ Dept. of Computer Engg. \\ JSPM's PVPIT, Pune
}

\author{
Varada Ketkar \\ B. E. (Computer) \\ Dept. of Computer Engg. \\ JSPM's PVPIT, Pune
}

\author{
Akanksha Bharti \\ B. E. (Computer) \\ Dept. of Computer Engg. \\ JSPM's PVPIT, Pune
}

\author{
H. V. Kumbhar \\ Assistant Professor \\ Dept. of Computer Engg. \\ JSPM's PVPIT, Pune
}

\begin{abstract}
This decisive evaluation discusses the review of road mishaps and car casualties in our country. Most of these are caused due to alcohol consumption by the driver's. Also many deaths occur due to lack of prompt medical attention needed to the injured person. This has been a matter of concern globally. This paper presents a compendious review of an integrated technique to detect alcohol consumption using face recognition. The existing techniques are not effective. The proposed system eliminates this bottleneck and make the entire detection system more robust. The above mentioned objective can be achieved with the help of embedded systems. The embedded system will control the speed of the car and take necessary actions.
\end{abstract}

\section{Keywords}

GSM Modem, GPS Module, Microcontroller, Indicator, Embedded System, Display, Location.

\section{INTRODUCTION}

There is an alarming increase in the morbidity and mortality due to four wheeler road traffic accidents. In India, it is estimated that one accident takes place every 2 minutes. Data from National Crime Record Bureau indicates that deaths and injuries related to road traffic accidents has increased two and four fold respectively during the period of 1991 to 2005. Reportedly, 98,254 persons were killed in 2005 on Indian Roads[6]. The occupants and drivers of four wheeler vehicles are among the majority to be affected in road accidents. One of the prime reason that leads to road accidents is drink and drive. Due to drinking and driving, four wheeler drivers often get into accidents. Almost $70 \%$ accidents in our country can be prevented if the drivers stop consuming alcohol.

This paper mainly focuses on the system which can have a control this activity. The system detects the drunken state of the driver and prevent the driver to move further[4]. This system also acts like a security mechanism or safety measure for the driver.

\section{LITERATURE SURVEY}

In 2015, Kenichi Takahashi, Kana Hiramatasu and Mami Tetsuishi presented Experiments on Detection of Drinking from Face Images Using Neural Networks and proposed a method to detect drinking state of a driver by using a camera, in order to prevent drunken driving[1]. The method detects whether a driver has drunken alcohol or not by using face images and their parts captured by a camera. It is also shown that parts, cheek, neck, and hand is useful to detect drinking[2]. In 2011, Wang Dong, Cheng Quan Cheng, Li Kai and Fang Bao-hua aimed at the serious phenomenon of drunk driving in modern society, a MCU electronic circuit board is used in the system. With alcohol sensor MQ303A, the alcohol concentration is detected. Through ADC0809, the detection signal is converted to digital signal, which is handled directly by MCU. According to the digital signal, the car is controlled automatically, can't be driving after driver drinking, thus avoid the occurrence of drunk driving. In 2016, Suparna Sahabiswas and Sourav Saha proposed an IoT based model with the aim to safeguard drunk and drowsy drivers especially at night. It includes analysis of alcohol concentration, eyeblinking rate and the rate at which the car is made to turn to detect a drunken or drowsy state and hence undertake protective measures[2]. Such measures include speed reduction, triggering an alarm, informing the traffic control, activation of auto-pilot etc. In 2012, Minoru Sakairi developed a system which involves the water-cluster-detecting (WDC) breath sensor. The WCD breath sensor detects breath by measuring electric currents of positively or negatively charged water clusters in breath that are separated by using an electric field. This is the first result that one device has been used to detect both drunk and drowsy driving. In 2010, Jiangpeng Dai and Jin Teng proposed a system to detect and alert the vehicles related to drunk driving. A program installed on mobile phone computes acceleration based on sensor readings, and compares them with typical driving patterns extracted from real driving. In 2010, T. Shyam Ramanath, A. Sudharsan and U. Felix Udhayaraj proposed a system to detect alcohol using infrared breath analyzer placed at steering wheel. In 2009, Yue-cheng Wu and Yun-qing Xia proposed the Design of an Automotive Anti-Drunk Driving System to Guarantee the Uniqueness of Driver. The system guarantees the uniqueness of the driver by combining the function of alcohol detection and face identification system, putting forward the design of combination of the alcohol main detection and the image processing auxiliary surveillance[5]. In 2011, J.Vijay and B.Saritha proposed a drunken drive detection system which efficiently checks the wearing of helmet and drunken driving. In case of any accident it would send the messages to the friends continuously about the location of the accident happened till the first aid reaches the driver. In 2008, Youngjae Kim, Youmin Kim and Minsoo Hahn proposed a system to detect driver fatigue. The system uses the driver's 
pedal controlling pattern with respect to the driver's front view situation. The system also uses a distance sensor on the frontend of the car so that it can capture an outside event. The entire sensor data are processed using a combination of Decision Tree learning algorithm and rule-based algorithm. In 2015, Vijay Savania, Hardik Agravata and Dhrumil Patela proposed a system in which alcohol detection sensor is used in the vehicle which senses and detects alcohol gases and continuously sends messages to the relatives[8].

The system proposed in this paper takes into consideration all the aspects and added features makes the system more robust and accurate.

\section{PROPOSED SYSTEM}

The proposed system mainly focuses on the detection of alcohol consumed by the driver. If the driver is found to be in drunken state, the system will prevent the engine from igniting or the system will slow down the engine if the car is in motion[3]. The buzzer is activated simultaneously. The system also sends an SMS regarding the location of the car to first five contacts so that immediate measures can be taken to reach near the car driver[7]. Figure 1 shows the proposed system block diagram and Figure 2 shows the system architecture.

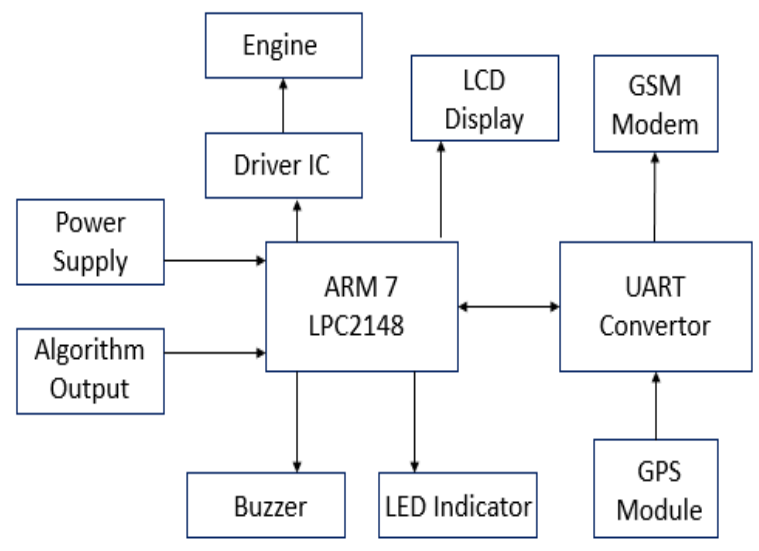

Figure 1: System Block Diagram

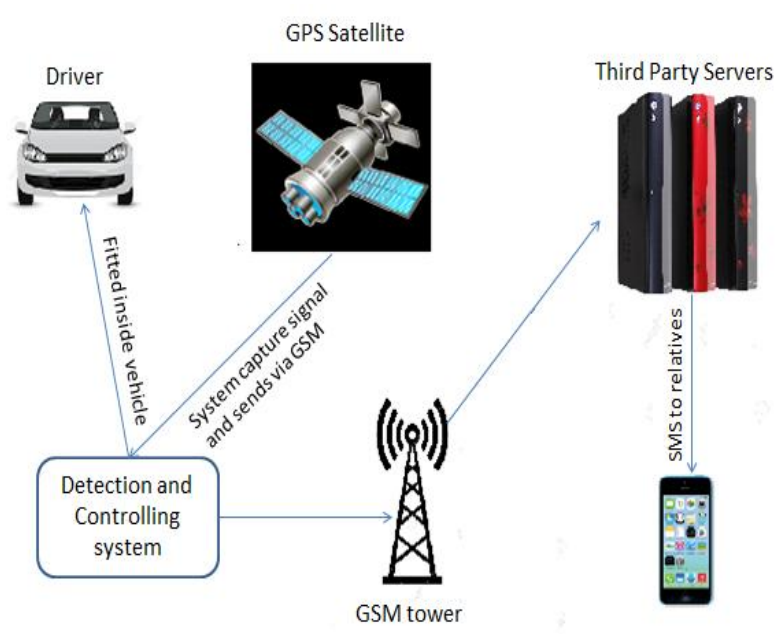

Figure 2: System Architecture

The system mainly comprises of two components :-
The Software components include embedded system software for interfacing hardware components like Night Vision Camera, LCD Display, Microcontroller, GPS System, GSM Module.

\section{B. Hardware Component}

The Hardware components include Night Vision Camera, Microcontroller, GPS System, GSM Module.

The proposed system works in two phases. In the first phase, when the driver turns ON the vehicle, the system detects the face images and generates relevant results[1]. If the driver is found to be in drunken state, the system prevents the engine from ignition and sends the SMS comprising of GPS location to the contacts present in the GSM Modem[4]. In the second phase, when the car is in motion and the driver is found to be in drunken state, the system will slow down the speed of the engine and come into halt state after a certain duration[5]. Simultaneously, the buzzer will be activated. Once the vehicle comes to halt state, the relevant GPS location in latitude and longitudinal form will be sent to the contacts present in the GSM Modem.

\section{Night Vision Camera :-}

The Night Vision Camera will capture the cheek images and continuously monitor the blinking of eye. These images will be processed and the signal will be sent to the microcontroller.

\section{LCD Display :-}

The LCD Display is placed inside the car. It displays the indication of alcohol detection and provide warning messages to the driver.

\section{Buzzer :-}

Once the system detects that the driver has consumed alcohol, the buzzer is activated.

\section{LPC2148 Microcontroller :-}

This system comprises of ARM7 LPC2148 Microcontroller. It is 64-pin IC which has single 10-bit digital-to-analog convertor providing variable analog output. This output is used to control the car engine.

\section{GSM Modem :-}

This system uses GSM 300 Modem which accepts any GSM operated SIM card. This modem is connected through serial port to the microcontroller. The moment at which the vehicle comes to halting state after alcohol detection, SMS is sent to all the contacts present in the SIM Card.

\section{GPS Module :-}

This system is used to notify the contacts about the location of the vehicle. This is a satellite based system compatible on 24 networked satellites located in the orbit.

A. Software Component 


\section{FLOW OF PROPOSED SYSTEM}

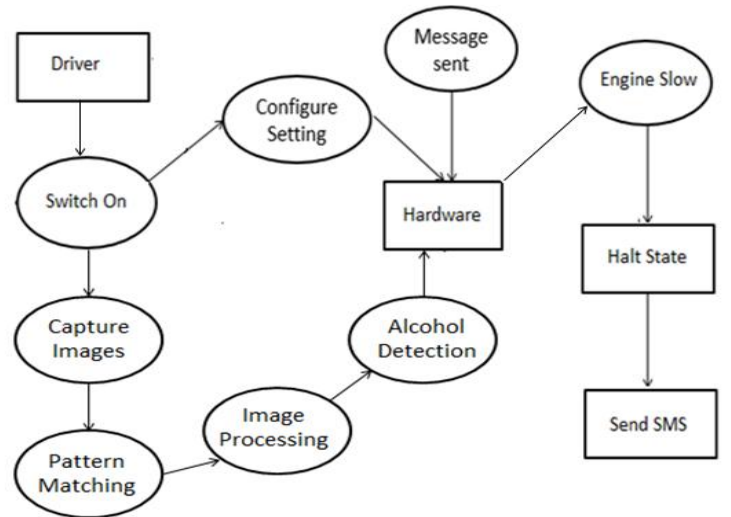

Figure 3: Flow of Proposed System

Table 1: Proposed Working of the System

\begin{tabular}{|c|l|l|}
\hline $\begin{array}{c}\text { Sr. } \\
\text { No. }\end{array}$ & \multicolumn{1}{|c|}{ Situation } & \multicolumn{1}{|c|}{ Expected Result } \\
\hline 1 & $\begin{array}{l}\text { If the driver is } \\
\text { normal }\end{array}$ & $\begin{array}{l}\text { Normal functioning of the } \\
\text { car }\end{array}$ \\
\hline 2 & $\begin{array}{l}\text { If the driver is } \\
\text { slightly drunk }\end{array}$ & $\begin{array}{l}\text { Normal function of the } \\
\text { car }\end{array}$ \\
\hline 3 & $\begin{array}{l}\text { If the driver is } \\
\text { moderately drunk }\end{array}$ & $\begin{array}{l}\text { Speed of the car will be } \\
\text { limited between 40 Kmph } \\
\text { to 60 Kmph }\end{array}$ \\
\hline 4 & $\begin{array}{l}\text { If the driver is } \\
\text { highly drunk }\end{array}$ & $\begin{array}{l}\text { Speed limit will be 20 } \\
\text { Kmph to 40 Kmph with a } \\
\text { message sent to the } \\
\text { contacts }\end{array}$ \\
\hline
\end{tabular}

\section{CONCLUSION}

It is due to increased consumption of alcohol, the percentage of accidents have increased lately. This paper presents a brief review of an integrated technique to detect alcohol consumption using face recognition. An efficient system is proposed to detect the alcohol consumption of the driver. This system is capable of fast processing of images using back propagation algorithm and react according to the results processed. The system immediately conveys the message to some of the important contacts of the driver. This system can be further extended by using auto-pilot mode in car. Also this system can be used in two wheelers for minimizing the drunken driving cases.

\section{REFERENCES}

[1] Kenichi Takahashi, Kana Hiramatsu and Mami Tetsuishi, "Experiments on Detection of Drinking from Face Images using Neural Networks", 2015 IEEE, 978-14673-9819-0/15

[2] Abhi R. Varma, Seema V. Arote, Chetana Bharti and Kuldeep Singh, "Accident Prevention using Eye Blinking and Head Movement", ETCSIT2012, IJCA

[3] Wang Dong, Cheng Quan, Li Kai and Fang Baohua, "The automatic control system of anti-drunk driving", ICECC, 10.1109/ICECC.2011.6067708

[4] T. Shyam Ramnath, A. Sudarshan and U. Felix Udhayaraj, "Drunken Driving and Rash Driving Detection", 2010

[5] Youngjae Kim, Youmin Kim, Minsoo Hahn, "Detecting driver fatigue based on driver's response pattern and the front view environment of automobile", IEEE2008, 10.1109/ISUC.2008.58

[6] Jiangpeng Dai; Jin Teng; Xiaole Bai; Zhaohui Shen; Dong Xuan, "Mobile phone based drunk driving detection",ICST Pervasive Health 2010

[7] Yue-cheng Wu; Yun-qing Xia; Pei Xie; Xiao-wei Ji, "The Design of an Automotive Anti-Drunk Driving System to Guarantee the Uniqueness of Driver",ICIECS 2009

[8] J.Vijay, B.Saritha, B.Priyadharshini, S.Deepeka, R.Laxmi, "Drunken Drive Protection System",IJSER 2011 